\title{
Correction to: Foundations of Chemical Reaction Network Theory
}

\section{Correction to:}

\section{Feinberg, Foundations of Chemical Reaction Network Theory, Applied Mathematical Sciences 202, https://doi.org/10.1007/978-3-030-03858-8}

The original version of this book has been revised because it was inadvertently published with a few errors.

\section{Chapter 3}

Page 24: In Definition 3.1.1., " $\left(y, y^{\prime}\right) \in \mathscr{R}$ ” has been updated to “ $\left(y^{\prime}, y\right) \in \mathscr{R}$.”

\section{Chapter 10}

Page 178: In Example 10.6.18, "Network (10.23)" has been updated to "Network (10.22)"

Page 190: In Equation 10.39, “ $t=1$, and $\ell=1$ ” has been updated to " $t=3$, and $\ell=3$ "

\footnotetext{
The updated version of this book can be found at https://doi.org/10.1007/978-3-030-03858-8_3

https://doi.org/10.1007/978-3-030-03858-8_10

https://doi.org/10.1007/978-3-030-03858-8_12

https://doi.org/10.1007/978-3-030-03858-8_13
} 


\section{Chapter 12}

Page 266: In the caption of Figure 12.13, " $c_{A S}-c_{B S}-c_{C}$ " has been updated to "... in a $c_{A S}-c_{A B}-c_{B_{2} S}$ "

\section{Chapter 13}

Page 278: On the right side of (13.11), " $f$ " has been updated to " $\mu$ "

\section{References}

Page 444: Reference 62 updated to https://doi.org/10.5281/zenodo.5149266

Page 445: Reference 78 updated to https://doi.org/10.5281/zenodo.5167618 